\title{
THE TIMING OF SURGERY FOR PROXIMAL FEMORAL FRACTURES
}

\author{
MARTYN J. PARKER， GLYN A. PRYOR
}

From Peterborough District Hospital

\begin{abstract}
We studied prospectively a consecutive series of 765 patients with proximal femoral fractures to determine if the time interval between injury and surgery influenced the outcome. Patients in whom surgery had been delayed for medical reasons were excluded. We divided the patients into four groups depending on the delay to surgery. Analysis of pre- and postoperative characteristics showed the groups to be similar. Mortality in the four groups was not significantly different but morbidity was increased by delay, particularly with regard to the incidence of pressure sores.
\end{abstract}

Surgical treatment for proximal femoral fractures is routine. Robbins and Donaldson (1984) found that patients with hip fractures waited an average 2.3 days in hospital until theatre time became available. The influence of this delay on recovery remains controversial.

It has been argued that after a fracture in an elderly patient, surgery should be delayed to allow for physiological stabilisation, correction of dehydration and preoperative treatment of any associated medical conditions. Kenzora et al (1984) and Schultz et al (1985) believed that mortality could be reduced by these measures.

Other studies have found it detrimental to delay surgery (Davie, MacRae and Malcolm-Smith 1970; Villar, Allen and Barnes 1986), while others have shown no difference between early and delayed surgery (Beals 1972; Davis et al 1988). Various criticisms have been levelled at these studies (May 1987), including failure to differentiate between those patients whose surgery had been delayed for medical reasons and those delayed for lack of theatre time.

Our aim was to study a larger group of patients, similar in all aspects except for the delay between injury and operation.

\section{PATIENTS AND METHODS}

This prospective study covers 765 consecutive admissions for proximal femoral fracture. We excluded 44 patients who were treated conservatively, and a further 90 patients because operation had been delayed to make the patient fit for anaesthesia. The reasons for the delay were

M. J. Parker, FRCS, Orthopaedic Research Registrar

G. A. Pryor, MS, FRCS, Consultant Orthopaedic Surgeon

Peterborough District Hospital, Thorpe Road, Peterborough PE36DA,

England.

Correspondence should be sent to Mr M. J. Parker.

(C) 1992 British Editorial Society of Bone and Joint Surgery

$0301-620 X / 92 / 2295 \$ 2.00$

J Bone Joint Surg [Br] 1992; 74-B:203-5. transfusion in 30 , treatment of congestive cardiac failure in 20, correction of dehydration and electrolyte imbalance in six, stabilisation of diabetes in five, treatment of chest infection in 18, and other causes in 11 . Three patients were lost to follow-up.

Initial analysis of the data showed that those patients with subcapital fractures treated by internal fixation were more likely to be operated on earlier and tended to be younger and fitter than patients treated by hemiarthroplasty or fixation of an extracapsular fracture. The analysis was therefore performed only on patients treated by hemiarthroplasty or by internal fixation of an extracapsular fracture with a dynamic hip screw (DHS) or a nail-plate. Twenty patients who had been treated by a variety of other implants were also excluded as they had more complex fractures.

Table I. Characteristics of the patients subdivided into four groups according to the delay (in hours) between injury and operation

\begin{tabular}{lcccc}
\hline & $\begin{array}{l}\text { Group A } \\
<24\end{array}$ & $\begin{array}{l}\text { Group B } \\
\text { 24 to 47 }\end{array}$ & $\begin{array}{l}\text { Group C } \\
\mathbf{4 8} \text { to } 72\end{array}$ & $\begin{array}{c}\text { Group D } \\
>\mathbf{7 2}\end{array}$ \\
\hline Number of patients & 161 & 129 & 69 & 109 \\
Hemiarthroplasty (\%) & 42 & 41 & 41 & 44 \\
$\begin{array}{l}\text { Mean hours from } \\
\text { injury to surgery }\end{array}$ & 14 & 31 & 61 & 145 \\
$\begin{array}{l}\text { Mean hours from } \\
\text { admission to surgery }\end{array}$ & 11 & 25 & 54 & 88 \\
Mean age (years) & 80 & 81 & 81 & 81 \\
Proportion male (\%) & 14 & 19 & 14 & 21 \\
Mean mobility score & 5.3 & 4.8 & 5.5 & 4.5 \\
Mean mental test score & 7.0 & 6.0 & 6.4 & 5.9 \\
Mean ASA grade & 2.5 & 2.5 & 2.4 & 2.6 \\
$\begin{array}{l}\text { Proportion from } \\
\text { residential homes (\%) }\end{array}$ & 28 & 32 & 22 & 39 \\
Mean haemoglobin (g/dl) & 12.4 & 12.5 & 12.4 & 12.4 \\
Mean serum urea (mmol/l) & 7.3 & 8.5 & 8.9 & 9.0 \\
\hline
\end{tabular}


This left 468 patients available for study. They were divided into four groups: group A in which surgery was performed within 24 hours of injury; group B between 24 and 47 hours, group $C$ between 48 and 72 hours; and group D more than 72 hours from injury. The reason for the interval between injury and operation was either that admission to hospital had been delayed or that a theatre or a surgeon was unavailable. No operations were delayed because of medical or therapeutic reasons. All patients were followed up for one year after the injury. The incidence of postoperative complications, the length of hospital stay and mortality were recorded for all patients.

The length of hospital stay was evaluated statistically between groups using a one-way analysis of variance and the $t$-test. Binary variables were analysed using the chisquared test and Fisher's exact test. A p value of $>0.05$ was considered not significant.

\section{RESULTS}

The characteristics of the four groups of patients are shown in Table I. Mobility was scored from 0 to 3 according to the degree of assistance required for getting about indoors, out of doors and for shopping (total score 9). The mental test score was based on a series of questions on cognitive function (Denham and Jefferys 1972), with a maximum score of 10 . The ASA grade is described by the American Society of Anesthesiologists (1963), and has been shown to predict early mortality following hip fractures (Valentin et al 1986).

Initial statistical evaluation of the four groups failed to show any significant differences. Because of this we performed a comparison of those patients who had surgery within 47 hours (groups A and B) with those who had undergone surgery more than 47 hours from injury (groups $\mathrm{C}$ and $\mathrm{D}$ ). The results are shown in Table II. The incidence of pressure sores refers to the percentage of patients who developed broken skin on either the buttock or heel area. There was a significantly reduced incidence

Table II. Comparison in percentages of patients who had early surgery with those who had late surgery

\begin{tabular}{|c|c|c|c|}
\hline & \multicolumn{2}{|l|}{ Groups } & \multirow[b]{2}{*}{$P$ value } \\
\hline & $\begin{array}{l}\text { A and B } \\
\text { Early surgery }\end{array}$ & $\begin{array}{l}\text { C and D } \\
\text { Late surgery }\end{array}$ & \\
\hline Incidence of pressure sores & 18 & 28 & 0.01 \\
\hline Confusional state & 21 & 13 & 0.05 \\
\hline Incidence of pneumonia & 8 & 11 & 0.30 \\
\hline $\begin{array}{l}\text { Incidence of pulmonary } \\
\text { embolism }\end{array}$ & 1 & 3 & 0.06 \\
\hline $\begin{array}{l}\text { Mean total hospital stay } \\
\text { (days) }\end{array}$ & 37 & 46 & 0.06 \\
\hline Mortality at 30 days & 10 & 9 & - \\
\hline Mortality at one year & 33 & 35 & - \\
\hline
\end{tabular}

of pressure sores in the patients in the early surgery group (chi-squared $=6.4, \mathrm{df}=1, \mathrm{p}=0.01,95 \%$ confidence limits $2.1 \%$ to $17.9 \%$ ). They did, however, have an increased incidence of confusional state after operation (chi-squared $=3.9$, df $=1, \mathrm{p}=0.05,95 \%$ confidence limits $0.7 \%$ to $14.3 \%$ ). There was a trend for those patients in whom surgery had been delayed to have an increased length of hospital stay and an increased incidence of pulmonary embolism and pneumonia, but these figures were not statistically significant. There was no difference in the mortality between the two groups.

\section{DISCUSSION}

Many factors influence the mortality and morbidity after a hip fracture. We have tried to reduce this bias to a minimum by studying a large group of patients treated by similar methods and excluding those who were initially considered unfit for surgery. The study was designed to be as objective as possible allowing for variables such as age, physical state, and cognitive state. We excluded patients with subcapital fractures treated by internal fixation as there was a tendency for the younger and fitter patients within this group to be operated on earlier and to have a better prognosis. Also the timing of surgery within this group of patients is influenced by evidence that early surgery will reduce the incidence of nonunion (Manninger et al 1989).

Further confirmation that each of our four groups is similar is shown by our analysis of the pre-operative characteristics of the patients. The mean mental test score before operation was slightly reduced in those patients treated later, but the difference was not statistically significant. Blood urea levels measured on admission tended to be higher in the patients in groups $C$ and $D$, reflecting the dehydration that may occur if admission is delayed.

The influence of delay of surgery on mortality remains debatable. Overton (1958) suggested that a period of 24 to 48 hours was necessary for appropriate pre-operative assessment of the patient and that this resulted in a reduced mortality. Kenzora et al (1984) also found an increased one-year mortality for those patients operated on within 24 hours of admission. However, Beals (1972) found no relationship between time from fracture to operation and hospital deaths, while Davie et al (1970) observed an increased mortality in those patients in whom surgery had been delayed for more than 48 hours in a series of 200 patients with trochanteric fractures.

Dolk (1985) and Villar et al (1986) found that patients operated on earlier had a shorter hospital stay, reduced postoperative complications and a better prospect for rehabilitation. Davis et al (1988), in a study of 230 patients with trochanteric fractures, did not confirm these findings.

In a recent review of patients treated in Sweden 
Dolk (1990), found no difference in mortality and hospital stay between patients operated on within eight hours of admission and those treated within $\mathbf{4 8}$ hours, indicating that there was no need to operate on these patients as emergencies. A confidential enquiry into peri-operative deaths (Buck, Devlin and Lunn 1987) recommended that surgery on high-risk patients should be undertaken or supervised by senior surgical and anaesthetic staff. Our study suggests that delaying the operation beyond 48 hours does not increase the mortality, but may increase the incidence of those conditions which are common in elderly bed-bound patients. We would advise that these injuries be treated within one or two days of admission, unless other medical constraints apply. It is reasonable to perform the operation during normal working hours when senior medical staff are readily available to participate in management.

No benefits in any form have been received or will be received from a commercial party related directly or indirectly to the subject of this article.

\section{REFERENCES}

American Society of Anesthesiologists. New classification of physical status. Anesthesiology 1963; 24:111.

Beals RK. Survival following hip fracture: long follow-up of 607 patients. J Chronic Dis 1972; 25:235-44.

Buck N, Devlin HB, Lunn JN. The report of a confidential enquiry into perioperative deaths. Nuffield Provincial Hospitals Trust/King's Fund London: 1987.

Davie IT, MacRae WR, Malcolm-Smith NA. Anesthesia for the fractured hip: a survey of 200 cases. Anesth Analg 1970; 49: 165-70.

Davis TRC, Sher JL, Porter BB, Checketts RG. The timing of surgery for intertrochanteric femoral fractures. Injury 1988; 19 : 244-6.

Denham MJ, Jefferys PM. Routine mental testing in the elderly. Mod Geriatrics 1972; 2:275-9.

Dolk T. Operation in hip fracture patients - analysis of the time factor. Injury 1990; $21: 369-72$.

Dolk T. When should the patient with a hip fracture be operated? Acta Orthop Scan 1985; 56:349.
Kenzora JE, McCarthy RE, Lowell JD, Sledge CB. Hip fracture mortality, relation to age, treatment, preoperative illness, time of surgery, and complications. Clin Orthop 1984; 186:45-56.

Manninger J, Kazar G, Fekete G, et al. Significance of urgent (within 6 h) internal fixation in the management of fractures of the neck of the femur. Injury 1989; 20:101-5.

May PC. Hip fractures in healthy patients (letter). Br Med J 1987; 294:119-20.

Overton LM. Fractures of the hip in the aged and disabled. Clin Orthop $1958 ; 11: 51-5$

Robbins JA, Donaldson LJ. Analysing stages of care in hospital stay for fractured neck of femur. Lancet 1984; 2 :1028-9.

Schultz RJ, Whitfield GF, La Mura JJ, Raciti A, Krishnamurthy S. The role of physiologic monitoring in patients with fractures of the hip. $J$ Trauma $1985 ; 25: 309-16$

Valentin N, Lomholt B, Jensen JS, Hejgaard N, Kreiner S. Spinal or general anaesthesia for surgery of the fractured hip? $\mathrm{Br} J$ Anaesth $1986 ; 58: 284-91$.

Villar RN, Allen SM, Barnes SJ. Hip fractures in healthy patients: operative delay versus prognosis. Br Med J 1986; 293:1203-4. 